\title{
Teachers educating to free women's based misconceptions
}

\author{
M. Ed. Marcela Montenegro
}

It has not always been easy to be a woman. Throughout history, women have been struggling to have a place in society and to be respected despite of different sacrifices and humiliations that they have had to face in their lives. As a matter of fact, in spite of living under specific rules or customs imposed by society, women have fought to raise their voices and make their rights known through courage, faith, and optimism. Hence, they could be accepted without any judgments and be part of society without any discrimination.

Unfortunately, these unfair standards, behaviors, and actions against women are still being repeated over and over again by men and women all around the world. Although there are more investigations and quality information about gender equality and women's issues, there are still different cultural patterns, customs, and misconceptions about women that are being unconsciously taught at different schools.

As a consequence, it is producing that these ways of being become universal and parts of a normal person's life. 
Therefore, it is the critically important duty or obligation of educators to realize and be aware of how these ideas are aftecting every person's life; and the way they can be changed by educating students in a meaningful, realistic, and fair way. As a result, there may be better opportunities for females to have equal rights, independence or to pursue what they wish in life and have both; men and women understand their real roles in society.

According to my experience as an English teacher, I have realized that in our educational system there are a lot of situations that need to be improved, so we can have better social environments. I am especially concerned about women's issues. This is causing a lot of problems in our society and mainly to the lives of different little girls, teenagers and adults.

I have experienced situations in which some of my female students have been mistreated by their parents, siblings, and other people only because of the fact that they are female. This has produced a negative impact not only in their learning process, but also in their lives. They live under a violent cycle, humiliations, and discrimination.

Also, I have asked myself as an educator a few questions that are related to this topic: What can we do as teachers to help students improve their situations? Are teachers being informed about gender equality? Are they trying to put that information into practice in their classrooms? Are teachers unconsciously reinforcing different behaviors and misconceptions against women in the classroom? What are they doing to do so? Are parents aware of different women's issues that are probably affecting their families?

Some of the things that have particularly caught my attention and that I would like to develop in this essay are the way little girls and boys interact and behave when they are with each other. Moreover, I would like to address the 
manner teachers reinforce situations of non-gender equality. Furthermore, I would like to talk about the use of didactic materials that in some cases don't promote gender equality which teachers implement in their classrooms and that are part of the students' formation.

Additionally, I would like to mention how the media and the environment are influencing females' perceptions of being an ideal woman and the way it is affecting many of them. Finally, I would like to propose several ideas or give advice of how teachers and parents can become more aware of the issues that are affecting many women's lives. I want to offer solutions for women to be able to improve the situations of inequality that they are facing or dealing with on a daily basis.

As it is known, the school is a place where most of the students that assist there learn society's norms. This includes how to behave in certain situations, how to interact with different people in order to be socially accepted, and how to develop the skills and capacities that will help them to be successful and productive in their communities among other positive aspects. On the other hand, it is true to say that in schools students learn oppressive mechanisms that limit their creativity and minds. Unfortunately, teachers contribute to these situations that are happening in the schools and that worsen the learning-teaching process.

There are certain ideas based on traditional societal schemes of how a boy or a girl should act during their social interactions, which still remain in many teachers' minds and influence students' personal growth. In the schools where I have worked, I have observed situations in which teachers separate the boys from the girls in the classrooms. They have stated that this is a good way in which boys stop bothering other girls and so on. Also, there are common phrases that teachers said to the girls in order to model their behavior. 
It is not perceived well that a girl acts in a rough way when they are meant to act delicate and conservatively. Consequently, teachers asked the girls to sit properly; otherwise some of the boys will see their panties. They also demanded that the girls didn't play tough games such as "ball", robber, hide and seek or smear the queer among others because they were considered too strong for the little girls who could be injured. Conversely, teachers proposed that the girls play "little house", jacks, school and perform other activities that don't have anything to do with boys' games.

In the mean time, it was interesting to notice that the girls that enjoy playing these kinds of games were considered "marimachas" and somehow they were rejected by the other girls. During recess time, these girls sat and spent time with their boy friends, rather than with their girl friends. They liked to joke, play, and fight among themselves and to be separated from the other girls' circles in which they didn't fit in.

It is important to take into account that this behavior varied according to the children's ages. For example, children that were in kindergarten were more prone to act conservatively and to play inside their classrooms with the toys that the teachers provided them. In this case, the students had already determined which toys were for the girls and the boys. The little girls played in a small wooden house with dolls, plates, brooms, and kitchen's items; and the boys played with sand, water and little cars.

In some situations, some of the boys wanted to play in the little house and the girls considered them as guests that needed a special attention. They cook for them, clean the house and have the boys relax and enjoy the food they prepared for them. It was just like a dramatization of the real life. 
In the same fashion, the students from first to third grade liked to perform more energetic activities that involved tougher games. Likewise, the students from fourth grade to sixth grade had other interests and performed activities according to their preferences. In the case of the boys, they liked to play "ball" or just to sit around. On the contrary, the girls liked to talk about different topics related to fashion, artists and beauty.

Among the phrases that I have heard teachers say to the students are: "Act as a normal and decent girl", "Don't get your blouse dirty, otherwise you'll look ugly", "Sit properly", "Avoid playing with the boys, if not you will be injured", "The boys are tougher and you are more delicate", "The boys don't bother cute girls" among other things that cause a great impact on the students' behavior.

All of the situations mentioned above show that girls are seen as weak and boys strong. Also, it is evident that girls are induced to perform household chores or other activities since very early ages as in kindergarten, differently than men that are supposed to perform activities in relation to cars or other activities that don't have anything to do with the house.

The gender role imposed by society is even more established during the primary school years. Society is reinforcing the concept that women are weak and inferior to men. This concept has been demonstrated by the fact that women are portrayed as being more delicate and soft in comparison to men who are perceived as being strong and more dominant than women.

Women are encouraged by society to stay away or avoid any activities that are "man-like" and only participate in female associated behaviors. What is really necessary to understand is that men and women are quite different because of nature. Males and females should be a complement to one 
another in which they share ideas, feelings, circumstances, and situations that allow growth and harmony between them.

It is of great importance to mention that teachers reinforce many of the cultural patterns that they learned in their families and environment during their teaching practice. There are still patriarchal ideas that govern their minds and that are transmitted to their students every day. Besides that, the educational system is based on a patriarchal scheme that also reinforces the behavior that most of the students have. As a result, it increases the misconceptions about the real women's role and allows these patterns to be repeated without any solution over the years.

Furthermore, some of the didactic materials that I used during my teaching process were oriented to fulfill each female and male social role. For example, some of the illustrations that appeared in many of the books, showed that the girls were meant to perform house chores, to work in jobs that are especially allotted for women, to act or dress as a "princesses" and to look beautiful as famous models among other things.

Besides that, the examples to follow as "role models" for the students were the well known singers and actresses that are really popular in the media nowadays. Nevertheless, there are a lot of negative behavioral aspects that are shown by this kind people and that the girls and boys are unconsciously copying.

As a matter of fact, I realized that during my teaching experience I used English text books that had more male than female illustrations. In many of the illustrations where women appeared, they were shown as being more passive, scary, conservative, and delicate than men. Also, the pictures presented women as symbols of beauty.

For example, in some of the English text books, the use of fairytales is a very attractive and common technique 
to grab the children's attention during their learning process. In many famous fairy tales such as Snow White and the Seven Dwarfs, Cinderella, Peter Pan, Sleeping Beauty, The Beauty and the Beast, and Brave Hero among others, women are seen only for their beauty and tenderness. The stories were decorated with beautiful colors, sceneries and people. The bad characters were the ugliest and they appeared in grotesque environments.

Besides encouraging imagination, creativity, humor, and positive moral messages, fairy tales can be a great source to teach English in different manners. Nonetheless, the subliminal message that the students internalize is what needs to be taken into consideration.

It is evident that these fairytales show that good things happen to people that are beautiful, that princesses are always going to be saved by a prince or knight, that the bad people are the ugliest, that there's always a need to be a savior that helps ladies which are in difficult situations and so on.

As it can be seen, there are two crucial aspects that play an important role in these stories which are beauty and power. The women that are beautiful have more probabilities to be happy" forever" and to conquer the handsome and brave prince that is rich and has a castle. Moreover, they also show that women are not capable of getting out of danger if they don't have a man around. In these situations, women can be seen as dependent and obedient of a man; otherwise they are not able to perform anything by themselves.

It also gives the idea that women need to be beautiful or almost a princess to be happy. What is really dramatic in this situation is that many little girls do believe in these stories. They want to be a princess. They want to have their prince charming that takes them away from any danger and poverty. The reality is different, though. 
Some of the girls that were in sixth grade of my school had their boy friends by that time and thought it was the most important thing that they could have in their lives. In this moment they are fourteen years old and have a baby. They didn't continue studying. They are living in their mothers in law's houses taking care of their babies and trying to survive against this unfair society. Their idea of the prince charming was totally different than the way they thought. The reality is different, but we as women need to deeply understand that situation.

Likewise, in the case of the jobs that a woman and a man need to perform, I have observed that in most of the text books' illustrations women are characterized and have the roles of nurses, flight attendants, secretaries, veterinarians, house wives, teachers, and other activities related to taking care of others.

On the other hand, men are meant to be police officers, fire fighters, taxi drivers, company managers, doctors, pilots, engineers among other activities that show they have control over certain situations. It represents that women are confined to perform duties that in the most part are no related to any position of power. It was difficult to find a picture in which women were presidents, the managers of a company, the ones that were heading an important scientific project, fire fighters, police officers, and others.

In addition to what was previously mentioned, I am especially concerned about the societal pressure that the girls receive in their daily lives. Also, the way it produces an impact on the perception of what it means to be a "WOMAN". In other words, the family, the media, and peer pressure have a lot to do with the way girls think and act. This can be observed at schools by the way they behave when they are around other girls and when they have a close friendship with the teacher. 
Nowadays, some people's ways of exaggerated consuming is becoming part of their normal lives. Every one is being influenced by the media to attain many things that are not vital for surviving. This is producing a lot of pressure, stress, emotional disorders, anxiety, and other things that are affecting many people's tranquility.

Consuming more than what is really needed reflects a part of the present societies and it is making people do different things to get what they want. Concerning this situation, women play an important role. It is true to say that the woman's image has become an essential aspect that grabs peoples' attention in general. They are seen as sex symbols and objects of beauty that make many companies, businesses and people become more powerful and gain a lot of money every day.

The woman's beauty is being used as a way to obtain power. As it can be seen, the distinct models, actresses and other famous women need to be almost perfect to be popular and well accepted in the media. There are some general characteristics that distinguish a "pretty woman", for example: being tall, thin, well formed, educated, and with fine features.

Also, there is a typical expression that is well known among ladies which is 90-60-90 and which suggests they have to fit in that prototype body to be "pretty". There are also women's beauty contests that reinforce even more the idea of the "perfect or ideal woman". Furthermore, in television, magazines, and advertisements among other ways of communication, they use the woman's image as an important mean to influence people to consume several items that the media offers as crucial things that every person should have.

Unfortunately, what this is making is that some women, especially teenagers, force themselves to act and do certain activities to fit into the present societal schemes. If 
they don't fit into societies' standards, some of the consequences that this situation brings along are health problems, discrimination, xenophobia, emotional disorders, eating disorders, alcoholism, drugs, suicide, low self esteem, and so on.

In the mean time, as a teacher, I have witnessed some behaviors that the girls have displayed during the school time and that are related to what was previously mentioned. The girls' self esteem is being damaged by the environment at a great rate. In their families, they are being raised under social standards that are wrongly based and that are provoking many social problems. Besides, during the school time, these kinds of situations are being reproduced over and over again increasing the women's misconception.

It is common to see, almost at the end of the school year teachers, parents, and community members promoting a "Beauty Contest" around my school. In this contest, one of the girls wins if they get more "votes" in comparison to the rest. However, the girls that participate are the ones that have more economical resources and support from their parents. The rest of the girls that don't have enough money and parents that are willing to help them during the process are not taken into account.

I have heard different comments from the little girls that couldn't participate in the activity. They said that if they had had the opportunity to do it, they would have worked hard to get all the necessary votes to be the "queen". Others said that they wanted to be there, but they weren't as popular as others to get many votes.

Something that I also noticed in my school is that during the scholar activities, only the same girls participated throughout the year. Although there were other girls encouraged to perform the same activities, they said that they weren't as popular, pretty, and talented as the ones that the teachers picked to carry them out. 
There could have been a more positive results and more overall participation from all the girls in the school, if the teachers had made more efforts to raise the self-esteem of all the girls. It would have been better to have seen all of the girls treated equally by all members of the teaching staff, but unfortunately the reality does not always result in this way.

Equally important is to mention that the girls' friendship groups mark a main facet during the students' growth process. The popular girls at the school were the ones that used the best brands, the ones that were considered pretty by the boys, the ones that in some cases didn't respect the norms, the ones that had "cool" school stuff, the ones that got along with the teachers better than the rest and the ones that participated in different popular school activities such as dances and theatrical performances.

They were looked up to by many girls that wanted to be like them in order to be popular. They copied their behaviors, so they could be renowned at the school and noticed by other boys. It is of great importance to say that this happened with the girls from fourth to sixth grade. Also, some of these girls' role models were the famous singers and actresses which are examples of bad behaviors, values, and feelings.

The rest of the girls weren't taken into account by the other admired girls. Furthermore, they weren't accepted in their friendships' groups and they were left behind in the activities that the popular girls were performing. In this case, the rejected girls had their own friendship groups and tried to enjoy being with each other. Nevertheless, these girls got better grades and had good behavior rather than the popular girls. If they couldn't be as popular as the rest of the girls, at least with good grades they could compensate their actions. 
It is evident that women are being pressured to be almost perfect. They have to be, act, and do certain things in order to be socially accepted. Women are suffering and dying from anorexia and bulimia. These two illnesses are affecting many teenagers' lives in many of the Costa Ricans' homes. It is more common to see a popular girl that is a model, rather than a president of an important company. What is worse is that although this is happening in real life, people don't realize how to stop this situation.

Besides, in many of the girls' minds the idea of being popular is connected with being thin and pretty against all odds. The women's self-esteem is suffering really bad and is still being damaged.

The situations mentioned before are a few examples of how the ideas about the gender role and women's misconception are being spread out at schools. Not only teachers are transmitting these thoughts; parents, friends, and relatives are also involved in this issue.

As it is known, the women's sense of inferiority is witnessed almost in every society. Actually, the roles of women were confined to a small list of responsibilities to fulfill in their lives. Some of the words that best described a woman were mother, housewife, and "pretty woman". Women were expected to stay home to cook, clean, take care of children, and any other aspect involving the house chores.

It is a realistic fact to see that most of the jobs that women still perform are related to cleaning, organizing and taking control of the house, office or other places. These were and in some cases are their sole responsibilities because there wasn't anything else they were allowed or expected to do.

This issue has to do with understanding the functions that women need to perform in society. The role of women needs to be understood not only by women, but by 
men as well. Consequently, they can improve different circumstances and situations that are causing a lot of troubles.

One class of society in general, is the inequality of the sexes. Men are the masters in economic, cultural, political and intellectual life, while women play a subordinate and even submissive role. Only in recent years women have come out of the kitchens and nurseries, but the essential inequality still remains.

This situation is witnessed around the world and Guanacaste is not the exception. Many women still live under oppression and ignorance about their real worth and value. Nevertheless, it is important to mention that women's self esteem, self image and education have a lot to do with this issue.

Some women are still thinking that they are only good enough to be in the house and take care of children. There are a lot of skills and capabilities that they haven't discovered yet. Therefore the challenge of many educators is to try to change these societal ideas and improve the social lifestyle that most people have. This battle has been taking place for years; it is not only for having equal rights for both women and men in society; but also to change unfair cultural standards in regards to women's roles.

As a result, I would like to propose some ideas and advice of how this situation can be improved during the teachers' daily teaching, school and families.

First of all, it is essentially important to inform parents, students, teachers, and community members about gender equality. It is indispensable to get professionals that have knowledge about women's issues. In this way, there can be conferences given to teachers, parents, students, and community members that broaden their knowledge and raise consciousness about the topic. 
The INAMU ( Instituto Nacional de la Mujer) is an institution that is willing to help the different schools that need help in these kinds of situations. This could be a good resource from which teachers and school's staff can take advantage of.

In order to do this, it is important to work with the orientation department in collaboration with the teachers, parents, and community members to maintain awareness of current events and conferences concerning women's issues. Also, it's crucial to promote these kinds of events with regularity, so that everyone will be updated and informed of situations that are affecting many homes. If all the people in the school environment are well informed about the various problems or difficulties that women are facing, they can work together to make positive resolutions in regards to these challenges. In other words, society can be improved on a daily basis.

Likewise, it is vital to reinforce analysis groups for teachers to be able to discuss diverse topics related to racism, discrimination, human rights, child abuse, cycles of violence, emotional disorders, and other important themes. As a result of these teacher focus groups, we can adapt learned subject matter and apply it within the classroom, so that students receive the same information as well. Although our curricular system is lacking information about current issues that happen in the community in general, we still have the obligation to look around and see what we face in order to improve it and adapt it in the curriculums.

It is the duty of the teachers to look for and adapt the didactic materials used in the classroom that promote gender equality. Also, teachers can use the current materials and textbooks to provide a different perspective for students to realize that they don't have to be limited to gender roles which have been placed upon them. 
For example, in the case of English subject matter, teachers can create their own activities or games related to different areas of study in relation to women's issues. As an example, instead of promoting the idea that women need to be beautiful or perfect in order to have success in life, they should be promoting the idea that it is fine just to be yourself and that each person is beautiful in their own way. It is really difficult for society to encourage the importance of developing inner beauty rather than superficial or exterior beauty. Unfortunately, this is what causes many problems for both genders, but especially for women to feel accepted by society's standards.

Teachers must read. Teachers need to be updated and read as much information as they can. It is almost unbelievable that teachers don't read books that can help them in their personal growth. So, it is necessary to raise consciousness among teachers to get books that are inspiring, motivational and encouraging for their teaching practice.

Also, teachers should develop activities inside the classroom that encourage students' cooperation with each other. There should be study groups in which girls and boys work together without being separated only for the fact of being males or females.

Teachers should be creative and implement techniques that help to diminish the abysm between students. In the case of English, it would be a good idea if movies are displayed with motivational and inspiring content. Even though some of the videos might be in Spanish, what is going to be developed in the class is going to be related to the language of English.

One of the major characteristics that teachers need to use during their teaching process is imagination. As I mentioned before, fairytales are an important didactic material to use during the class to teach grammar structure, to 
have students talk and to do role plays among other things. For that reason, teachers need to create their own stories, giving a different message in which women's passive roles are not reinforced.

It is necessary that teachers promote workshops for women, so they have more opportunities to learn about their options in society. During these workshops mothers and other women from the communities can discover abilities and skills they didn't know they had and put them into practice.

In this way, they can improve their self esteem and realize they are very important people that can do a lot for society and themselves. Also, they can empower themselves and reinforce their inner strength to overcome difficult situations that they have to face on a daily bases.

Besides, female and male students can also receive workshops according to their ages to improve gender equality. This is the duty of teachers and parents to carry them out. The main purpose of these workshops is to create consciousness among the girls and boys of how they need to treat each other, creating an equal environment.

Additionally, it is important, that students get information in a very creative way of how women and men have been raised in society. This is crucial to understand the real roles of women and men. They need to understand that women are not only capable of performing house chores. The permanent idea that women are only good enough for taking care of children and performing activities in which they are in charge of taking care of others, needs to be varied. The boys also need to share these kinds of responsibilities without feeling that they are inferior or weak.

During school celebrations, teachers need to promote the participation of different boys and girls. They have to include, if possible activities in which most of the students can participate without making them feel pressured. 
A song, a poem, a dramatization or even a game can be good resources that involve many learners at the same time. In this way, they are not going to feel rejected and left out of essential activities held during the school year.

It is also of great importance to eradicate contests of beauty and popularity around the schools. There can be other ways of raising money for the school. For example, fund raisers such as food sales, carnivals, dances, and bingos among others.

A good way to promote creativity and artistic expressions is that students create their own paintings or art pieces and sell them to the community. Avoiding these kinds of beauty contests, the fatal idea that physical beauty is the only way that women can be famous can be eliminated little by little.

The advice and optional activities mentioned before are some of the things that can help many people (teachers, parents, students, and community members) to understand that there are a lot of situations that need to be improved in order to have a better social environment. The situations that many women are facing are only a small piece of the problems that are happening around the world, but they are necessary to be addressed.

An essential aspect that every person needs to have in order to grow personally, spiritually, and professionally is attitude. Everything can be possible if everyone decides to make the right choices and to put them into practice. This can also help people around grow too.

What has happened to women around the world is not a new topic to develop. What causes me a great worry is that women are still living under discrimination, unfair standards, and humiliations. The worst thing is that these situations don't stop. It caused me a great concern that although there's a lot more of information about women 
issues and revolutionary movements in favor of women's rights among other things, people continue suffering from societal schemes imposed by ourselves.

I do believe teachers are the ones that can promote changes and offer a different perspective to the life of different women. They only need to have faith, courage, and an open mind for a revolution to take place in the societies where we live. The change can be done with a positive attitude towards the future. 